\title{
RELATIONSHIP BETWEEN CHANGES IN TECHNOLOGICAL CULTURES AND SPATIAL DEVELOPMENT OF CITIES
}

\author{
DOI: 10.18485/arh_pt.2020.7.ch63
}

\section{_ Dmitrii Klimov}

Director, State Autonomous Institution of the Moscow region «Research and Design Institute of urban planning», 47 Gilyarovskogo street, Moscow, 129110, Russian Federation, dmcompass@mail.ru; Ph.D. (economical), Associate Professor, Moscow State University of Civil Engineering (National Research) (MGSU), 26 Yaroslavskoe shosse, Moscow, 129337, Russian Federation

\section{_ Sofiia Feofanova}

Master student of the Department of Urban Development, Moscow State University of Civil Engineering (National Research University) (MGSU), 26 Yaroslavskoe shosse, Moscow, 129337, Russian Federation, sonyafeofanova@mail.ru

\begin{abstract}
The article is devoted to the relationship between changes in technological cultures and the spatial development of cities. To study the relationship between changes in technological cultures and spatial development of cities, the authors use the following methods: theoretical, including analysis and modelling; general scientific method, including literature analysis, generalization, comparison, systematization of empirical and theoretical data; practical method based on the experience of urban planning. The purpose of this study is to identify, formulate, and parameterize patterns of interaction between changes in technological cultures and spatial development of cities. The authors reveal the basics of the interaction between participants in urban development activities in the same territory. Special attention is paid to the issue of forecasting and creating a high-quality spatial organization of the urban environment.

The significance of this study for the professional community is to determine, organize, and describe the patterns of interaction between changes in technological cultures and spatial development of cities. The practical significance of this work is forecasting the spatial development of cities in connection with changes in technological cultures, the increase of the quality of life of the population by urban planning means.
\end{abstract}

KEYWORDS_technological culture, spatial development, urban planning, quality of life of the population

\section{INTRODUCTION}

The city, being a complex urban-planning formation, successfully functions due to its systematic structure. For the population, it consists of functionally different parts that complement each other, and are interconnected and interdependent, e.g., housing - work - recreation (leisure, entertainment). The city is a unique socio-cultural phenomenon that has influenced the entire course of world civilization. Cities have given birth to the forms of self-organization of citizens by place of residence and various types of self-government. The city is undergoing changes in the process of social development. Cities have grown at the intersection of trade routes or developed from religious centers 
and have undergone changes in the course of the evolution of society. At first, the housing in the cities of traditional feudal-agrarian society performed a defensive function and had the appropriate appearance. At the same time, trade was carried out mainly on the basis of barter, and leisure and entertainment could be any outdoor activities - all kinds of more or less mass events - from games, and any competitions to the shows of stray artists, and a variety of musical performances with singing and dancing, etc.

During the industrial revolution, new cities have grown out of enterprises. The isolation of production and, as a consequence, trade functions is a key feature of the city at a certain stage of its development, as the German sociologist Max Weber wrote [1]. Another German researcher Friedrich Ratzel confirmed the decisive role of trade in the genesis of the modern city, adding other features to the attributes of the trade - the concentration of housing and minimum population size [2]. However, the selection of these features was uncertain and lacked sufficient scientific justification. Apartment buildings providing comfortable living conditions for the population near the places of employment have appeared. Trade and monetary relations are actively developing in the process of the production and sale of goods. The industrial society makes a step forward in terms of leisure and entertainment. It develops a network of cultural, entertainment, and sports facilities, building amusement parks as well as adding touristic and recreational components.

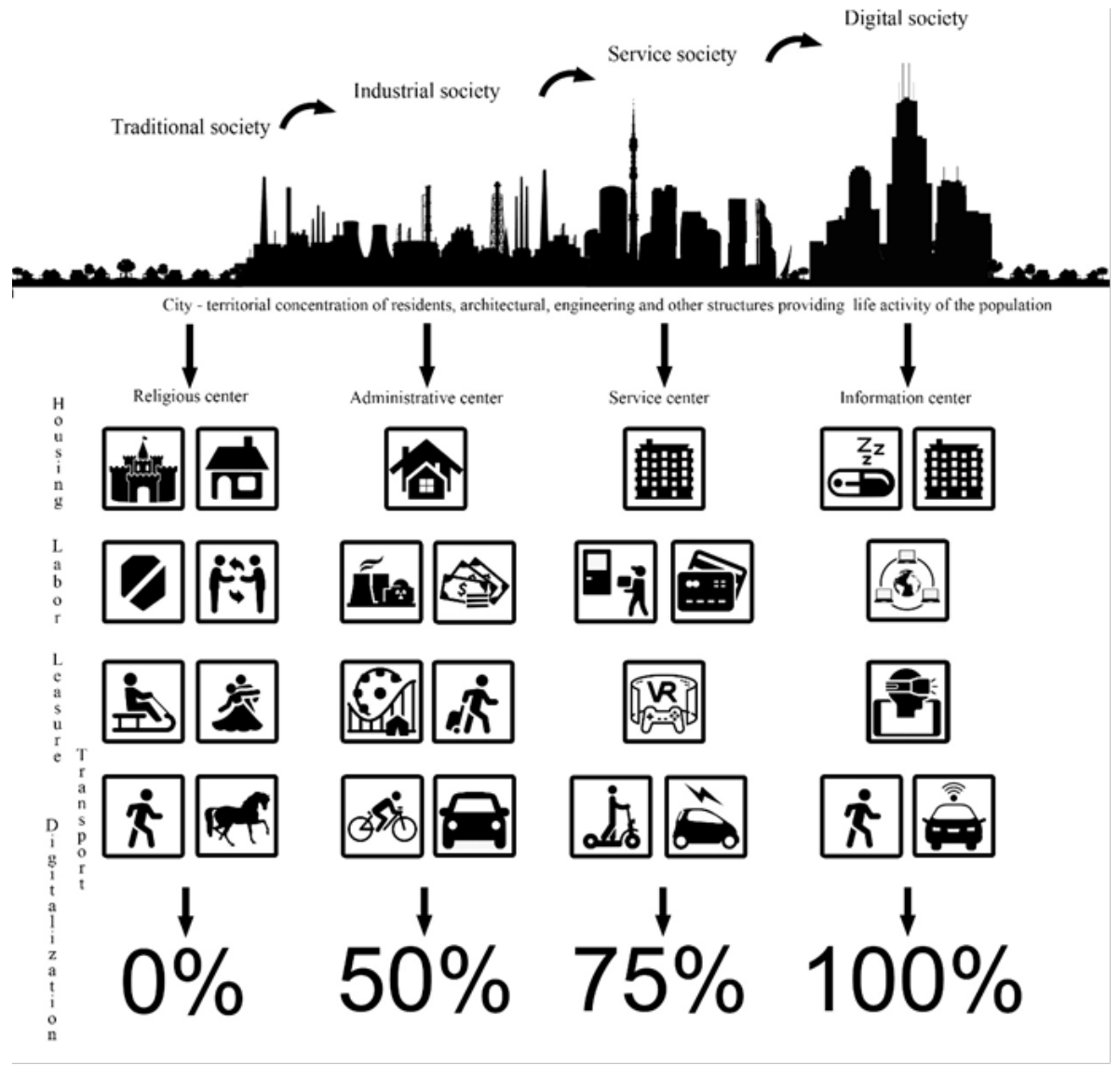

_ Figure 1: Changes in the functional content of cities

At present, intensive urbanization going worldwide is steadily increasing the trend towards the compaction of urban development and, consequently, the more efficient use of space. Along with the 
housing of comfort and business class, small apartments, created to meet the needs of contemporary society, appear in modern cities' new residential complexes. Almost all services are now becoming remote.

The rapid transition of consumers to the electronic format of trade is due to the fact that Internet commerce has developed, in part, to compensate for the inadequate development of physical retail formats. The low level of the development of financial institutions and banking infrastructure also contributed to the rapid spread of online financial services. The virtual reality that has recently emerged was created in response to the demands of the digital society. Thus, according to modern requirements, the need to spend leisure time without leaving one's home is realized - with the help of a computer, VR glasses or a helmet you can find yourself at the premiere of a theatrical performance or a show, in a movie theater, take a trip or find yourself in an exciting game.

In the future, the reduction of living space will reach the size of a capsule $-2.5 \times 1.5 \mathrm{~m}$. Population density will increase even further, and work will take on a remote character globally. The tools of augmented reality that are already being created will speed up the acquisition of information. Digitalization, robotization, cybernetization are the qualitative definitions of future life in a digital society. Thus, digital processes have already challenged the traditional sphere of education and traditional jobs, making the conception of life-long learning in order to accelerate changes in professional activity, the most important trend of our time.

Information technologies have led not only to the digitization of business processes and social life but also to a radical transformation of the very essence of the city. Digitalization processes in many areas of urban planning have already become total and irreversible.

The described processes are schematically shown in Figure 1.

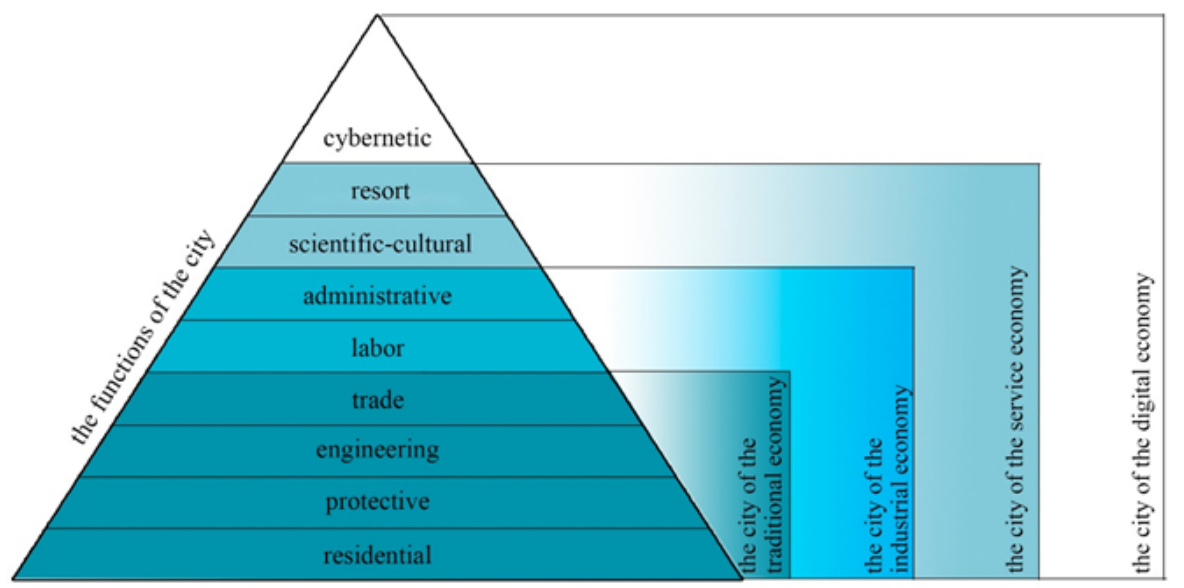

_ Figure 2: The Diagram showing the pyramid of the city's functions

In order to visualize the changes in the city's functions within the historical perspective, the authors of the publication [3] created a pyramid of the city's functions analogous to the Maslow's pyramid of human needs (Fig. 2). Thus, the fundamental functions of the cities of all types are residential, protective, engineering, and trade. They are the starting point for the "city of the traditional economy". The next stage of development - "the city of the industrial economy", becomes such due to the creation of the places of employment in the form of manufactures; at this point, administrative and command management appears.

At the next stage - the "cities of the service economy" develop culture, science, including monitoring of environmental welfare, as well as tourism and recreation activities.

In its turn, the "city of the digital economy" combines all historically established functions and manages them with the help of the cybernetic principle that states that the management system should 
correspond to the level of the complexity of the managed natural-technical system.

The presented pyramid illustrates the appearance of functions in cities. The traditional society's city had only half of the existing functions. The industrial revolution added administrative and labor components to this system. The scientific and cultural activities of the population brought additional functions to the city. The resort towns are the typical representatives of the "service economy". The digitalization of these functions will be the final stage in the formation of a digital city. The city space with objects whose development, implementation, and further operation meet the criteria of " $4 \mathrm{E}$ " - ecology, economic efficiency, effectiveness, and ergonomics is perspective [4]. Figure 3 presents a comparative analysis of the functions of cities with different modes of the economy. The pictograms show the fundamental technological changes in society.

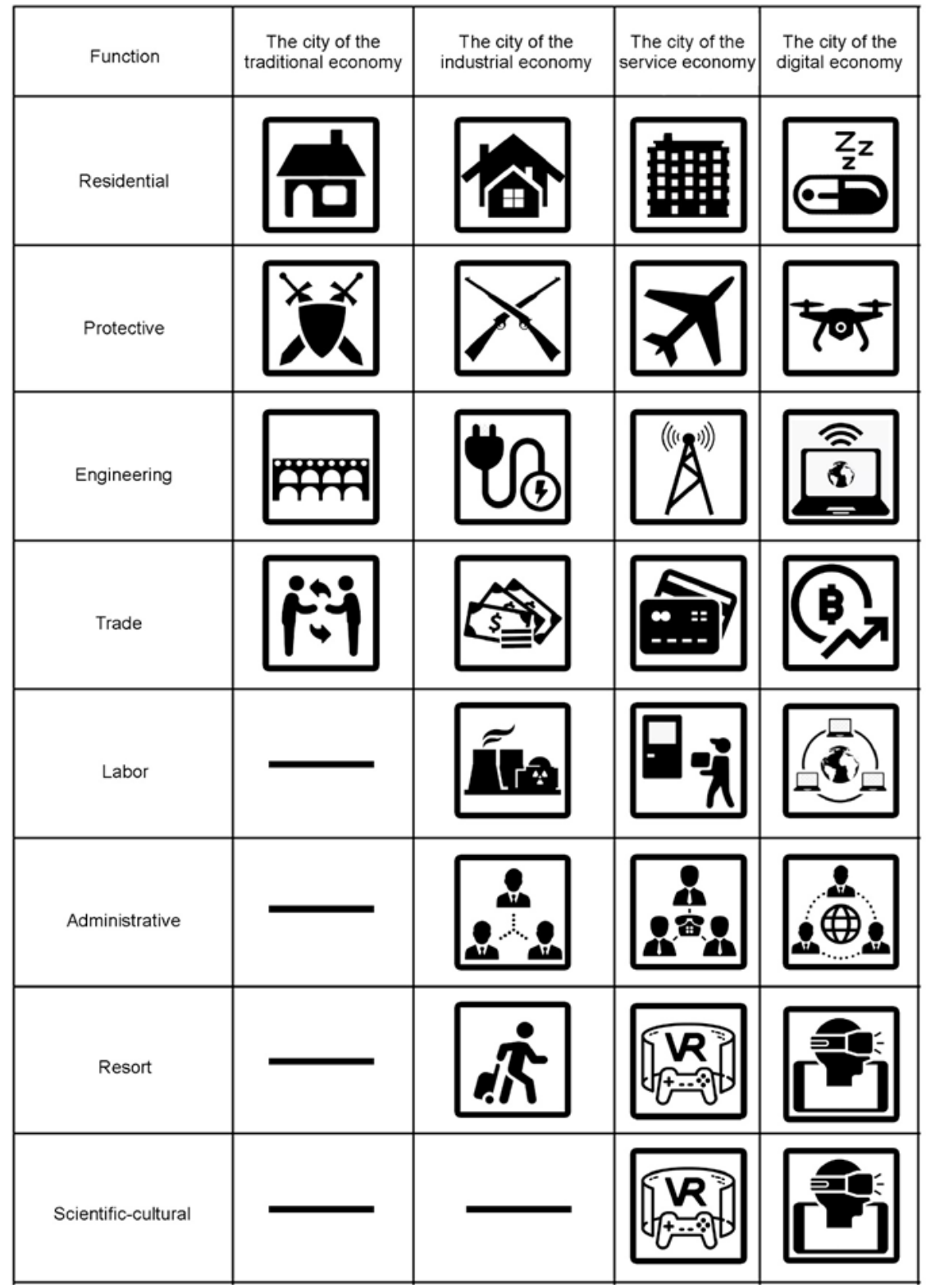




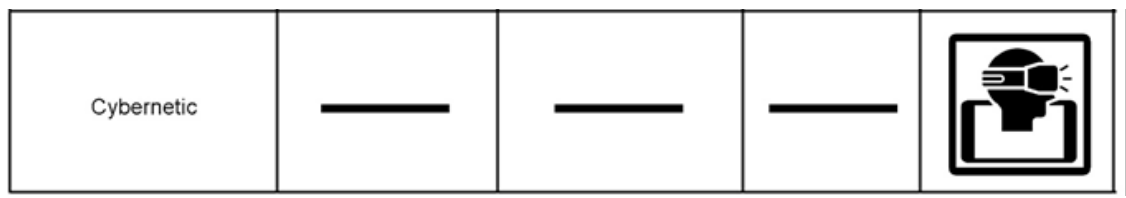

_ Figure 3: Comparative analysis of the functions of cities with different economic patterns

The balance of functions helps to compare objects of similar purpose - urban spaces of the cities of different economic modes in this case - by the number of functions and assess their changes (Fig. 4).
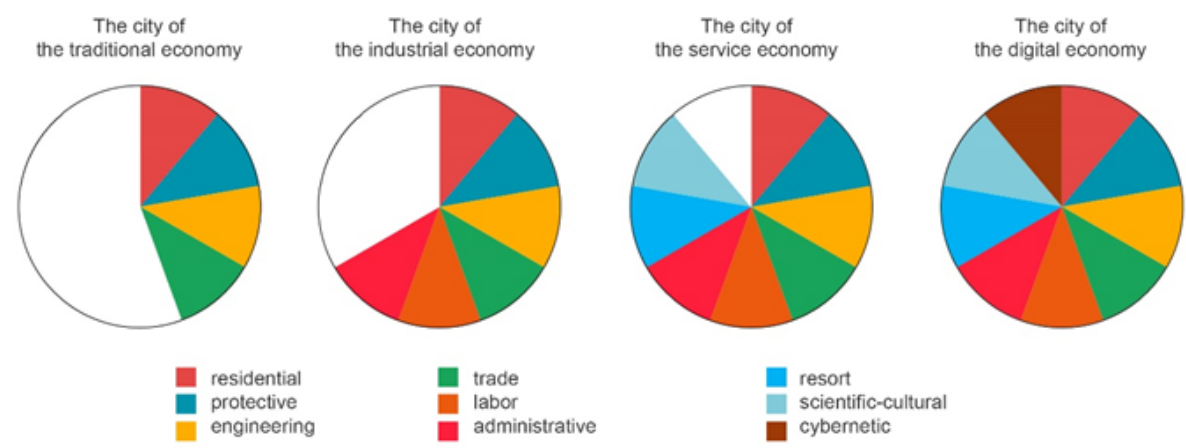

_ Fig. 4 The diagram of the balance of functions of the cities of different economic models.

The purpose of digitalization is to formulate and implement the best practices of digital development in the subjects of the Russian Federation. Among them is the effective urban policy and replication of technologies and solutions in the field of information and communication technologies to improve the quality of life [5].

Digital urban planning

_ The digital economy makes it possible to create a single hierarchy at all levels of urban planning.

_ All functions of urban planning - analytics, research, and forecasting - are based on structured digital information. Accurate calculations, the formation of data banks, and the development of information systems make it possible to create digital topographic maps and digital city plans. Digital modelling methods in the field of public transport communications, based on mass high-quality data collection and analysis, are essential for the development of effective urban management systems.

_ By 2025, 50 "smart cities" will appear in Russia.

The digitalization of the city covers the following areas: education, health care, management, housing and communal services, transport, recreation and leisure, environmental control.

\section{CONCLUSIONS}

Let's forecast the possible consequences of the development of the region, the municipal entity, the city. The digital city does not attach importance to the location of the employee, which contributes to the spread of the polycentric model of territorial management. Remote jobs allow people to work from anywhere in the world. Globalization will increase competition between people in the labor market. There will be an outflow of population from existing cities. The population will be distributed on the Pareto $80 / 20$ principle. 
The functions of the existing cities will be distributed in their respective territories. Only super-center cities, with $20 \%$ of the population, such as Moscow, Tokyo, New York, etc. will remain. The rest of the population will be evenly distributed over the territory, which eliminates the need for administrative boundaries. The mobility of the population will decrease, which will lead to a decrease in the intensity of the use of all types of transport. Uniform settlement ensures a comfortable living environment proportionate to the person's needs. Coworking centers for remote work and entertainment centers for leisure activities will be built. The society will return to the traditional city but in a different quality...

\section{REFERENCES}

- Maslow, Abraham. 2014. Motivation and Personality. Saint-Petersburg: Piter. https://www.livelib.ru/ author/16596/top-abraham-harold-maslou

- Presidential Grants Fund. The "Digital Region" Project.

_ https://президентскиегранты.pф/public/application/item?id=38634631- 1 efe-43e2-bd4a$574 \mathrm{e} 80 \mathrm{f0} 272$

- Ratzel, Friedrich. Ethnology. In 2 Volumes. 1903. Saint-Petersburg: Printing House of the "Enlightenment" Partnership. https://www.geopolitica.ru/article/fratcel

- Roderick, Y. A. et al. Comparative Study of Building Energy Efficiency Assessment Between LEED, BREEAM, and Green Star schemes. Integrated Environmental Solutions Limited, Kelvin Campus, West of Scotland Science Park, Glasgow, G20 0SP, United Kingdom

- Weber, Max. The City. Selected Works. 1990. Translated from German and edited by Y. N. Davydov. Moscow: Progress. pp. 309-446. Electronic publication: Centre for Humanitarian Technologies. https:// gtmarket.ru/laboratory/basis/3597 